\title{
Mechanical Characteristics and Failure Modes of Low-Strength Rock Samples with Dissimilar Fissure Numbers
}

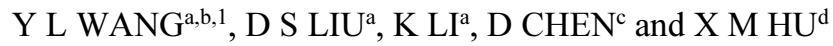 \\ ${ }^{a}$ Chongqing Bureau of Geology and Minerals Exploration, Chongqing 401121, China \\ b State Key Laboratory of Coal Mine Disaster Dynamics and Control, Chongqing \\ University, Chongqing 400044, China \\ ${ }^{\mathrm{c}}$ Chongqing Vocational Institute of Engineering, Chongqing 402260, China \\ ${ }^{\mathrm{d}}$ Chongqing Gaoxin Engineering Survey and Design Institute Ltd., Co., Chongqing \\ 401121, China
}

\begin{abstract}
The mechanical characteristics and failure modes of low-strength rock sample with various crack dip angles and numbers were investigated by conventional uniaxial compression test and three-dimensional (3D) crack reconstruction. The results indicated that compared with high-strength rock masses, cracks had different influences on the low-strength rock mass mechanical deformation features. Thereinto, the number of fissures can cause post-peak failure stage of stress-strain curve change from swift decline to multi-step down and horizontally extended decline, respectively, showing obvious ductility and ductileflow deformation and failure characteristics. Due to the structural effect, only under the condition of fissure $\alpha<90^{\circ}$, the modulus of peak strength and elastic modulus lowered with the enhancement of fissure number and had a negative correlation. As the number of fissures increased, the axial peak strain increased first and then decreased, demonstrating a reversed V-shaped change trend. Fissure number can fully affect the crack propagation law only in the case of vertical fissures. The above research findings can complement and improve the study of fissured rock masses.
\end{abstract}

Keywords. Low-strength specimen, pre-existing fissure, mechanical property, failure mode, 3D-crack reconstruction

\section{Introduction}

There exist substantial primary and structural fissures in engineering rock masses. The objects directly faced in geotechnical engineering are rock masses with certain structural characteristics, mainly composed of structural bodies (rock) and complex structural surfaces (joints, fissures, etc.) [1-3]. With the development of geotechnical investigation methods and further research on rock mechanics, people have gradually recognized that under the influence of geological environment and engineering disturbance, the expansion and interpenetration of fissures are the main failure modes of engineering rock masses. Thus, it will be very imperative to learn the mechanical

${ }^{1}$ Corresponding Author, Y L WANG, Chongqing Bureau of Geology and Minerals Exploration, Chongqing 401121, China; Email: 860024333@qq.com. 
and deformation failure traits of fissured rock masses, and it also has engineering value for engineering excavation and stability analysis.

To comprehend fissured rock mass deformation and failure modes, considerable experimental studies have been correspondingly conducted. From Bombolakis [4] acquiring the failure properties of pre-fissured samples with uniaxial compression, many fissured rock experiments were explored to attain their deformation and strength behaviors. For instance, the scientists [5, 6] also researched strength and deformation attributes of pre-fissured marble in conservative uniaxial compression and triaxial compression. Moreover, complete and imperfect samples owned various deformation aspects with the peak stress, and the mode of peak strength and failure relied on fracture geometry and the confining pressure. Shen [7] researched fracture beginning in rock-like materials and described three kinds of material failure, including shear, tensile and mixed failures. Moreover, Wong and Einstein [8] summarized former literatures and concluded effects of fissure geometry (fissure angle, ligament length and angle) upon fracturing procedure and coalescence pattern of Carrara marble samples with two exposed cracks. Also, Yang and Jing [6] conducted uniaxial compression researches on a sand stone sample including a crack to learn impacts of single crack angle and length on the deformation and strength failure performance. Furthermore, based on two pre-existing transfixion fissures with triaxial compression, Xiao et al. [9] worked on the failure traits of marble, and determined that anti-wing cracks were chief form of cracks that influence the eventual failure mode of samples. These reports are that with uniaxial, biaxial or triaxial compression, concentrated on mechanical properties and crack propagation law of pre-fissured samples with single $[10,11]$, double $[8,12,13]$ or multiple $[14,15]$ rectangular defects. Compared with uniaxial and biaxial compression tests, triaxial compression tests are rare, mainly because triaxial compression tests can simulate the real environment of the rock mass, but cannot directly observe the initiation and expansion of new cracks. Relative to uniaxial and biaxial compression tests, it is rarely seen triaxial compression tests, which tests can fake the practical surroundings of rock mass, but cannot straightly perceive new fissure initiation and expansion. Besides, the constituents applied to produce the pre-fissured specimens can be separated into two groups: rock-like and real rock materials. There exist numerous rock-like materials, e. g., glass, Columbia Resin 39, cement, molded gypsum, and various mixed materials $[12,16]$. The real rock material are mainly highhardness rock masses, such as granite [17], marble [18, 19], granodiorite [8, 20], limestone [21], sandstone [6]. Meanwhile, the methods of pre-existing cracks mostly contain laser, hydraulic, and blade cutting, and pre-buried fissure, etc. True rock samples are primarily processed by the first three means, and the rock-like material samples are commonly treated by pre-buried fissures. Usually, pre-buried fissures and blade cutting are applied based on production price and technical requirements of the specimens,

The above experiments have obtained abundant findings, which own vital guiding meaning for learning mechanical features, crack propagation principles and deformation instability characteristics of fissured rock masses. However, there still exist many deficiencies in relevant research at this stage, which can be summarized as follows:

(1) Most experimental works were restricted to conservative compression tests on high-strength rock masses of pre-fissured samples, but the investigation of mechanical belongings and failure modes of low-strength rock examples with pre-existing cracks was still rare. In wildlife, rock masses with low strength frequently comprise extra 
major joints and fissures than rock masses with high strength, which can possibly generate secondary fissure beginning and expansion, leading to the total unsteadiness and failure for the rock mass.

(2) Whether it was a conventional compression test or a numerical simulation test, the experimental conclusion was mostly based on the analysis of the two-dimensional image or the cutting face of the specimen during the test. Although the experimental results obtained had certain research significance, the original and secondary cracks in the rock specimen both initiated and expanded in three dimensions. The final failure of specimens was also the result of the interaction between cracks. Thus, the simple twodimensional analysis cannot fully reflect the fissure start and propagation law and the final failure mode of samples.

Thus, it is critical to systematically explore the mechanical attributes and real three-dimensional failure mode of fissured rock masses with low strength. To more profoundly acquire strength, deformation, and crack coalescence patterns of rock samples with low strength, conventional uniaxial compression tests and threedimensional (3D) crack reconstruction were performed on sandy mudstone rock-like material samples with dissimilar fissures geometries (fissure dip angles and numbers). The experimental results can further supplement and perfect the research in related fields of fissured rock masses and enrich its research methods.

\section{Experimental Methodologies}

\subsection{Specimen Preparation}

Low-strength rock masses can be established as UCS smaller than $30 \mathrm{MPa}$ [22], and the sandy mudstone was chosen under the average value $28.23 \mathrm{MPa}$ of UCS, from a mine in Sichuan, China. It hardly created specific cracks in practical rocks. Thus, the study used rock-like materials to conduct experimental investigation in associated parts. The existed experiments suggested a strong similarity between mechanical parameters and other characteristics of rock-like or rock materials [16]. In other words, it is achievable to apply rock-like materials to substitute rock materials for exploring mechanical principles and failure modes.

From indoor matching trials, cement mortar with mass ratio for water: sand (80 mesh): cement (32.5 grade) of 0.4: 1.0: 1.0: was selected to form sandy mudstone rocklike materials. The basic physical and mechanical parameters of real sandy mudstone and rock-like materials are shown in table 1. Moreover, figure 1 suggests the uniaxial compression relationship between stress and strain and crack patterns of the complete rock-like specimens and sandy mudstone samples. From table 1 and figure 1, it can be seen that the failure modes and mechanical properties and of the two specimens are in good agreement, demonstrating the feasibility of using rock-like materials samples rather than sandy mudstone specimens for more investigation. The pre-present cracks were through-opened fissures, formed by pre-buried steel bars. According to the method proposed from the International Society of Rock Mechanics, the prepared specimens had cylindrical shape (diameter $50 \mathrm{~mm} \times$ height $100 \mathrm{~mm}$ ) $100 \mathrm{~mm}$. Figure 2 indicates numerous sorts of rock-like specimens exhaustively. The crack geometry of the pre-fractured sample can be determined: $\alpha$ is the fissure inclination angle, $2 \mathrm{a}$ and $2 \mathrm{~b}$ are corresponding to the fissure length and width, while $2 \mathrm{~L}$ is the rock bridge length. 
Moreover, the pre-present cracks were positioned in the sample middle to minimalize influences of end friction on the experimented specimens.

Table 1. Basic parameters of rock-like material and sandy mudstone.

\begin{tabular}{llllllll}
\hline Type & $\begin{array}{l}\text { Density } \\
\boldsymbol{\rho}\left(\mathbf{g} \cdot \mathbf{c m}^{-3}\right)\end{array}$ & $\begin{array}{l}\text { UCS } \\
\boldsymbol{\sigma}_{\mathbf{c}}(\mathbf{M P a})\end{array}$ & $\begin{array}{l}\text { Tensile strength } \\
\boldsymbol{\sigma}_{\mathbf{t}}(\mathbf{M P a})\end{array}$ & $\begin{array}{l}\text { Elastic modulus } \\
\mathbf{E}(\mathbf{G P a})\end{array}$ & $\begin{array}{l}\text { Poisson } \\
\text { ratio v }\end{array}$ & $\begin{array}{l}\text { Cohesive } \\
\text { force } \mathbf{c}(\mathbf{M P a})\end{array}$ & $\begin{array}{l}\text { Internal frictional } \\
\text { angle } \boldsymbol{\varphi}\left({ }^{\circ}\right)\end{array}$ \\
\hline $\begin{array}{l}\text { Sandy } \\
\text { mudstone }\end{array}$ & 2.42 & 28.23 & 2.54 & 7.25 & 0.22 & 22.68 & 31.8 \\
$\begin{array}{l}\text { Rock-like } \\
\text { material }\end{array}$ & 1.96 & 27.08 & 2.32 & 5.88 & 0.25 & 20.42 & 33.7 \\
\hline
\end{tabular}

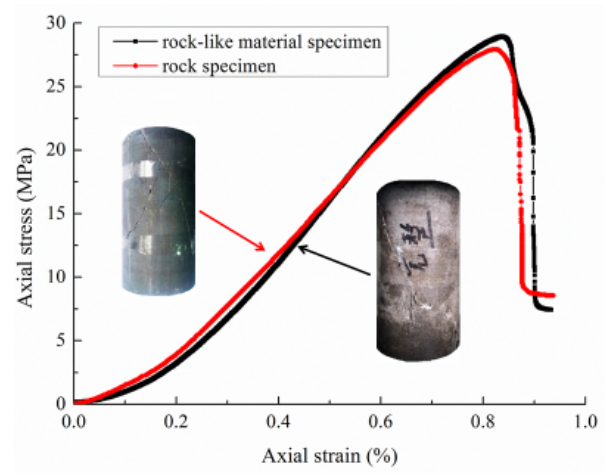

Figure 1. Uniaxial compression stress-strain relationship and failure modes of samples of sandy mudstone and rock-like materials.
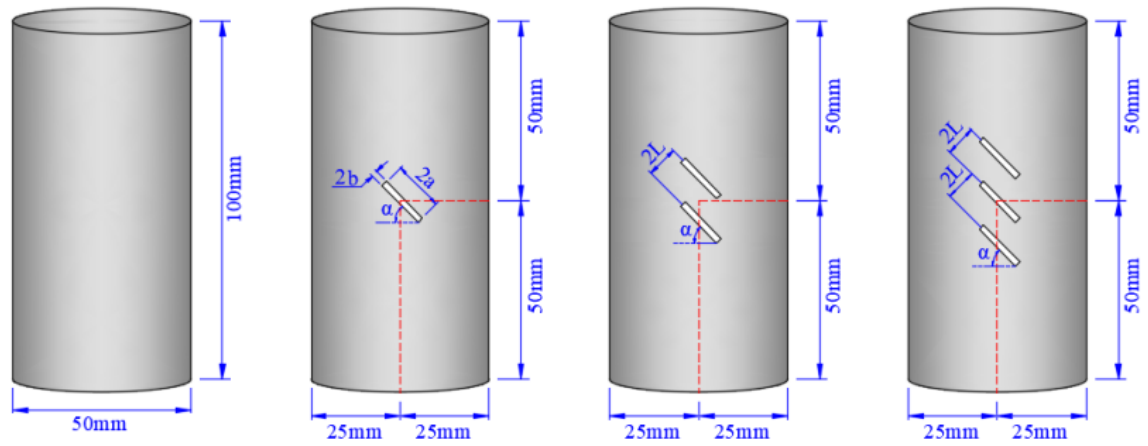

Figure 2. Dissimilar geometric pre-present cracks in rock-like material specimens.

To study the impact of dissimilar geometric pre-present cracks on the mechanical properties and failure modes of sandy mudstone samples, one experimental scheme was schemed in the article: Multi-cracked samples had diverse numbers. 2a was $15 \mathrm{~mm}$ and $2 \mathrm{~b}$ was $2 \mathrm{~mm}, \mathrm{~h} 2 \mathrm{~L}$ was $10 \mathrm{~mm}$, and $\alpha$ included the angles of $0^{\circ}, 30^{\circ}, 60^{\circ}$ and $90^{\circ}$. The number of fissures $\mathrm{n}$ is corresponding to 1 to 3 . Table 2 indicates the detailed test scheme. To lower the dispersion of test outcomes, three pre-present fissure samples were made for each influence factor. Under the identical experimental circumstances, three parallel examinations were conducted to confirm the efficiency of the experiment. The standards followed: (1) The failure modes of samples should be principally same; (2) It should own a close stress-strain curve. Meanwhile, two specimens at least can 
satisfy the criteria, and if possible, additional samples can be employed for repeatability trying.

Table 2. Strategy of examination scheme.

\begin{tabular}{llll}
\hline No. & Examination scheme & Geometric variable & Geometric invariant \\
\hline $\mathrm{I}$ & $\begin{array}{l}\text { Multi-cracked samples with } \\
\text { diverse number }\end{array}$ & Single, Double, Three & $\begin{array}{l}2 \mathrm{a}=15 \mathrm{~mm}, 2 \mathrm{~b}=2 \mathrm{~mm}, 2 \mathrm{~L}=10 \mathrm{~mm} \\
\mathrm{a}=0^{\circ}, 30^{\circ}, 60^{\circ}, 90^{\circ}\end{array}$ \\
\hline
\end{tabular}

\subsection{Testing Procedure and Reconstruction Method}

For MTS 815 rock mechanics servo control test systems, the complete and pre-fissured rock-like samples are subjected to conservative uniaxial compression examinations, and the maximum axial load capacity is $2800 \mathrm{KN}$. Experiments applied displacementcontrolled quasi-static loading mode using a fixed rate of $0.002 \mathrm{~mm} / \mathrm{s}$ till a failure happened. First, two short cylindrical rigid steel blocks with the equal diameter were located on both ends of the specimen as the experimented sample. Besides, applying a moderate petroleum jelly to the contact surface between the sample end and the steel block can expressively lower the impact of end friction on experimental outcomes. In the process of loading, the fissure start and expansion of sample were recorded using a high-definition camera for later analysis.

By combining CT scanning with Avizo software processing, 3D-crack reconstruction was performed. CT scanning technology has the advantages of lossless, dynamic, quantitative detection, and high-resolution digital image display. Also, Avizo software possesses the characteristics of $3 \mathrm{D}$ visualization and data direct output. First, a CT scan was conducted on the pre-fissured specimens after uniaxial compression test with the Micro XCT-400 test system. After that, Avizo 8. 0 software was used to process the scanned slices by median filtering, binary processing and finely processing in turn, as shown in figure 3. Finally, the processed 2D scanning slices were reconstructed to acquire $3 \mathrm{D}$ digital specimens. After crack extraction, a 3D-crack reconstruction model could be obtained. The detailed process is shown in figure 4 .
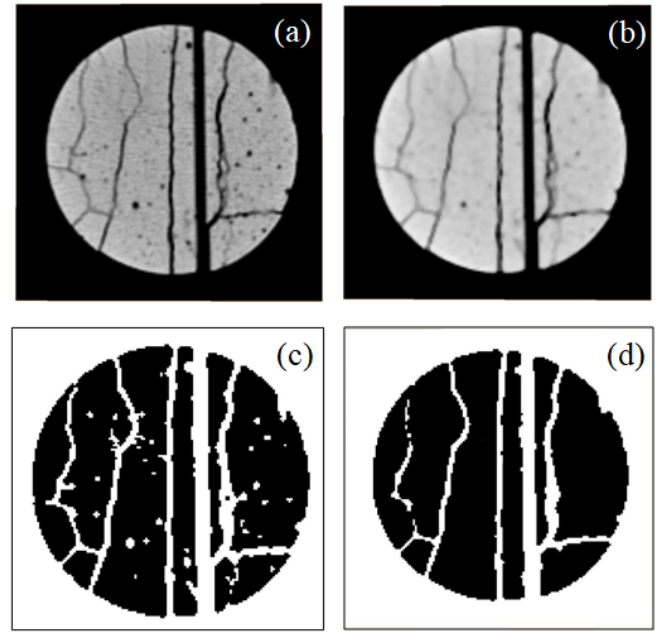

Figure 3. Processing of CT scanning diagram.
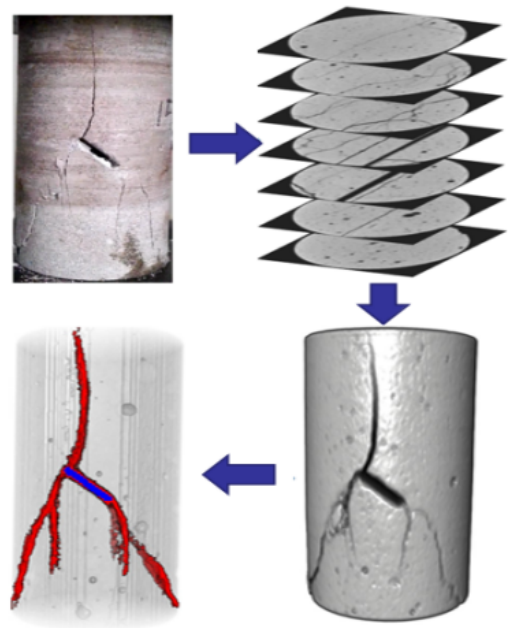

Figure 4. Process schematic diagram of 3Dcrack reconstruction. 


\section{Experimental Results}

According to the uniaxial compression test and 3D-crack reconstruction results, this section analyzes the mechanical belongings and distortion failure features of lowstrength pre-fissured specimens.

\subsection{Strength and Deformation Properties}

Figure 5 shows the stress-strain relationship of pre-fissured samples with various crack numbers at dip angles of $0^{\circ}, 30^{\circ}, 60^{\circ}$ and $90^{\circ}$. Specimens with more fissures had lower peak strength (UCS) and smaller peak strain. Besides, as crack number increased, linear range of stress-strain curves decreased gradually, which indicated that the elastic modulus lowered with growing fissure number. Meanwhile, the number of fissures had the most significant effect on the post-peak failure stage of stress-strain curve. If fissure dip angle was smaller than $90^{\circ}$, as increasing fissure number, stress-strain curves gradually altered from swift decline to stepwise one, and finally became a slow horizontal extension decline. This indicates the ductility of fissured specimens gradually increased, and eventually the overall ductile characteristics appeared. Also, this progressively varied from brittle failure to ductile failure, and finally to ductileflow distortion and failure. This phenomenon was most pronounced in horizontally multi-fissured specimens, but not in the high-strength rock samples. However, if fissure dip angle was $90^{\circ}$, fissure number owned no noticeable impact on stress-strain curve, and post-peak failure stage decreased rapidly, which was brittle failure. This is primarily since when the fissure path was parallel to axial stress direction, the fissures will damage the sample integrity, but it had insignificant impacts on the bearing capacity of specimens influenced by structural effects. The closer the crack dip angle was to direction of main stress loading, the more apparent structural effects, efficiently mitigating the damage influence of fissures on specimens.

Figure 6 describes the peak strengths of samples with various crack numbers at $0^{\circ}$, $30^{\circ}, 60^{\circ}$ and $90^{\circ}$ fissure dip angles. Consequently, the impact of the fissure number on peak strength was mainly divided into two types, namely deterioration $\left(\alpha<90^{\circ}\right)$ and fluctuation $\left(\alpha=90^{\circ}\right)$. If fissure dip angle was smaller than $90^{\circ}$, peak strength decreased noticeably with increasing fissure number, suggesting that crack damage effect on samples enhanced with growing crack number. If crack inclination angle was $90^{\circ}$, the peak strength fluctuated slightly with enlarging fissure number. This was largely due to that the vertical fissure undermined the integrity of specimens, but the cutting effect of fissures will form a multi-columnar bearing structure in the central part of specimens, so it had little influence on the bearing capacity.

From figures 5 and 6, it can be known that the increase of horizontal and inclined fissure number can greatly influence the mechanical properties of specimens.

In figures 7 and 8, the axial peak strain and elastic modulus of samples with dissimilar crack numbers were statistically analyzed, which can well reflect the deformation characteristics of the specimens.

In figure 7, the elastic modulus of samples under diverse crack dip angle generally decreased as crack number increased. If fissure dip angle was $0^{\circ}$, the decreasing trend was most pronounced. Yet, with increasing crack dip angle, this decreasing trend will be gradually weakened. If the crack dip angle enlarged to $90^{\circ}$, the elastic modulus was only slightly varied with enhancing fissure number. This phenomenon was mainly due to the following two reasons: (1) Horizontal fissures were more easily deformed and 
closed than compressed inclined and vertical fissures. As increasing crack number, the deformation and closure of each fissure will accumulate to a certain extent. This leads to a weakened of specimen's resistance to deformation and a decrease in the overall elastic modulus. (2) If fissure dip angle increasing, the compression deformation of fissures gradually decreased, but the structural effect was gradually dominant, thus relieving the damage impact of crack number on elastic modulus.
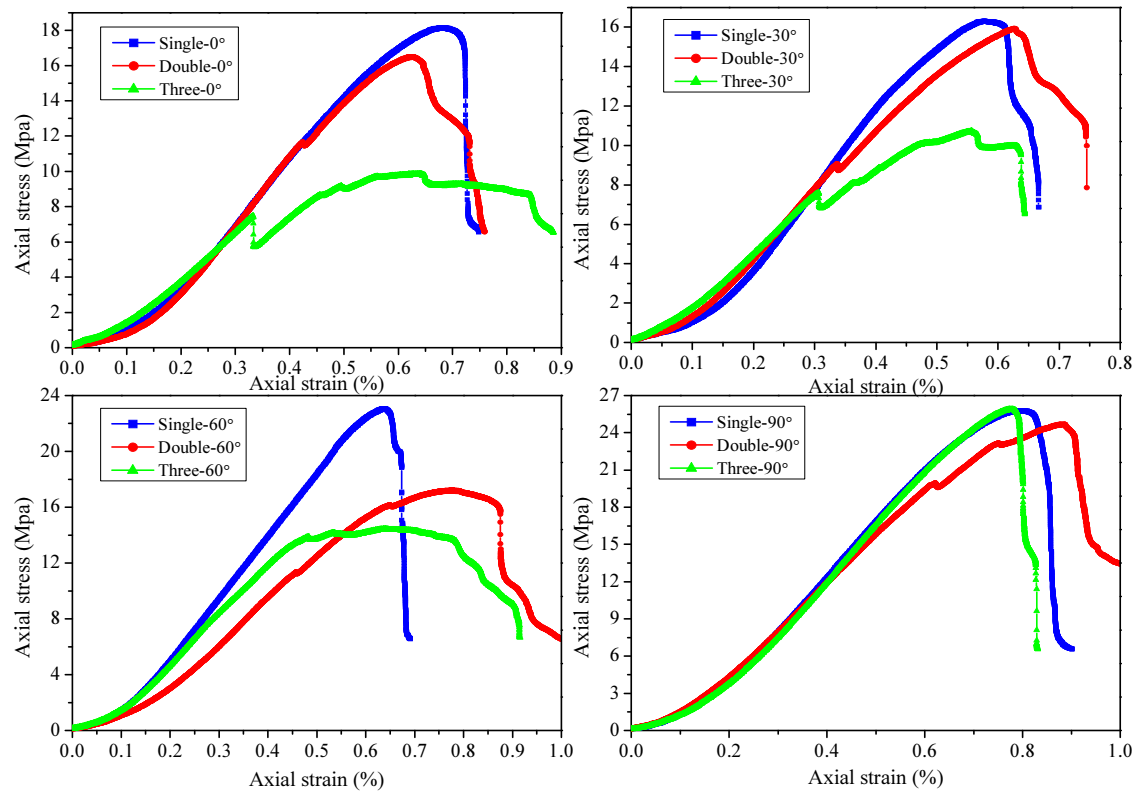

Figure 5. Stress-strain curves of pre-fissured samples with various crack numbers.

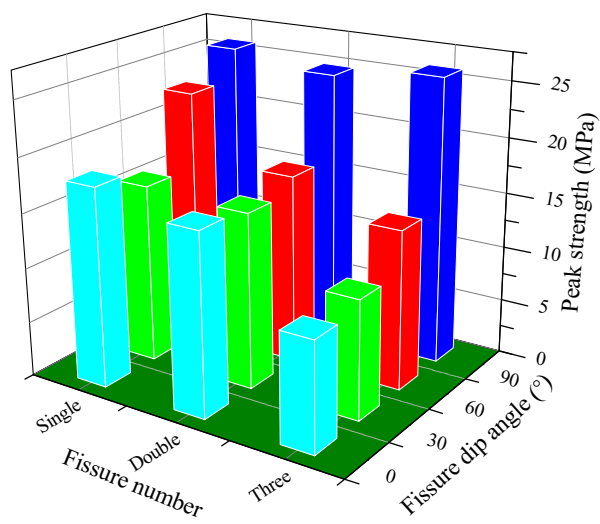

Figure 6. Peak strength of pre-fissured specimens with dissimilar crack numbers.

As demonstrated in figure 8, under different fissure dip angles, the axial peak strain of pre-fissured sample owned an inverted V-shape tendency, which also increased first and then lowered with growing fissure number. This was mainly due to the existence of fissures, which can terminate integrity of specimens and diminish their bearing capacity. Thus, due to fissure number increasing, specimens can have great 
distortion under the condition of small axial stress. Nevertheless, if fissure number continued to increase, the bearing capacity of samples can be significantly abridged. Under trivial stress conditions, multi-fissured specimens can be destroyed, and this resultant axial peak strain will be reduced.

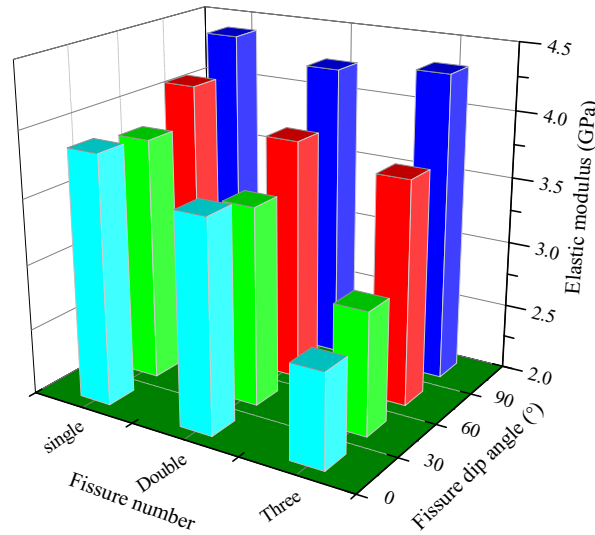

Figure 7. Elastic modulus of pre-fissured samples with dissimilar crack numbers.

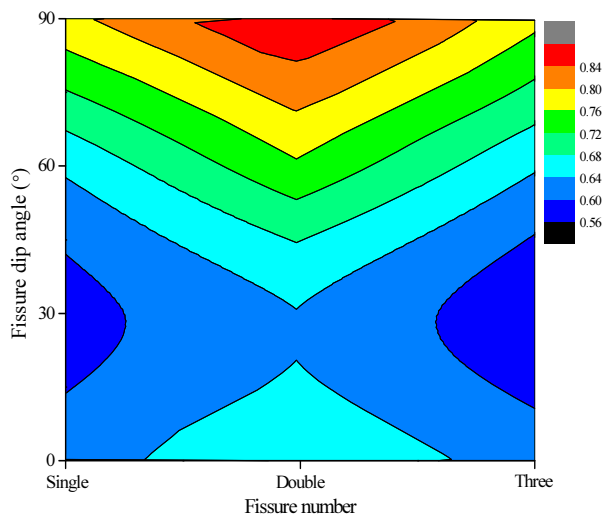

Figure 8. Axial peak strain of pre-fissured samples with diverse crack numbers.

From figures 7 and 8, fissure number increment, especially inclination and horizontal fissures, can own a large influence on distortion features of specimens.

\subsection{Crack Propagation and Failure Modes}

Figure 9 shows three-dimensional reconstruction of crack propagation in the samples having dissimilar crack numbers and fissure inclination angles.

From figures $9 \mathrm{a}, 9 \mathrm{e}$ and $9 \mathrm{i}$, it can be concluded that at $0^{\circ}$ crack inclination angle, the increase of fissure number had insignificant effects on fissure propagation and failure pattern of specimens. They were all typical tensile failure caused by the extension of the initiation tensile cracks to the specimen boundaries. The pre-fissures were also interconnected by tensile cracks initiated at their ends. In figures $9 \mathrm{~b}, 9 \mathrm{f}$ and $9 \mathrm{j}$, the failure modes of $30^{\circ}$ fissured specimens cannot be changed with increasing fissure number, remained as tensile-shear composite failures. However, crack propagation form had a relatively large variation. As the fissure number increased, the cracks no longer germinated from the middle part of fissure, and all of them developed at the ends. The new tensile or shear cracks kept relatively parallel and extended to the boundaries, resulting in complete loss of the bearing capacity of specimens. The fissures were mostly connected by shear cracks initiated at the ends. The fracture patterns of multi-fissured specimens under the condition of $60^{\circ}$ fissure dip angle are shown in figures $9 \mathrm{c}, 9 \mathrm{~g}$ and $9 \mathrm{k}$. It can be seen from the diagrams that sample failure was generated by extension of tensile and shear cracks from fissure tips to the upper and lower boundaries. The main fracturing cracks were Y-type distribution overall, as a typical tensile-shear composite failure. As shown in figures 9d, 9h and 9l, the failure modes and crack propagation of $90^{\circ}$ fissured specimens had changed prominently because of increasing fissure number. Thereinto, under the condition of single fissure, the specimen was typical single-slope shear failure, and the shear crack was skewed 
with the original fissure and passes through the specimen. With double fissures, the specimen became a tensile failure caused by numerous vertical tensile cracks. These vertical cracks converged at the axis of the specimen, causing the specimen to burst and lost its bearing capacity. For three fissures, sample failure was triggered by shear fissures developed between the pre-fissures in the central part, which were connected to each other and extend to the left and right boundaries.

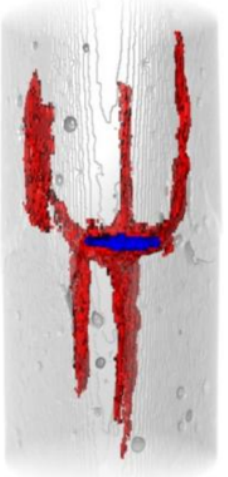

(a) Single- $0^{\circ}$

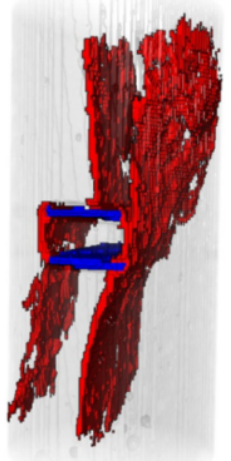

(e) Double- $0^{\circ}$

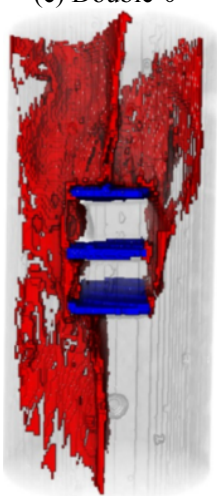

(i) Three- $0^{\circ}$

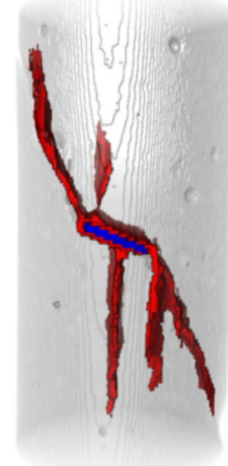

(b) Single- $30^{\circ}$

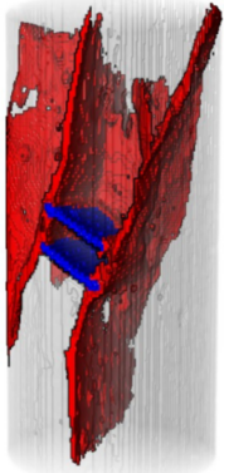

(f) Double- $30^{\circ}$

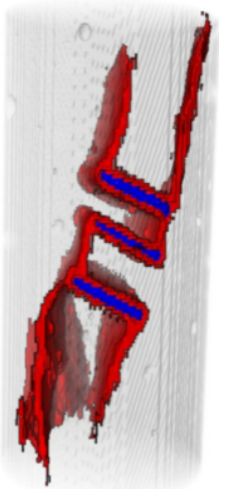

(j) Three- $30^{\circ}$

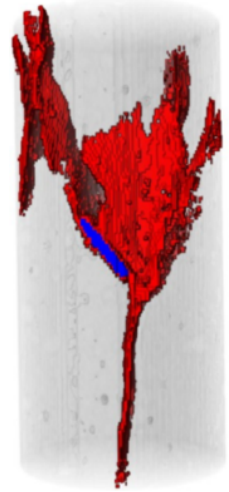

(c) Single- $60^{\circ}$

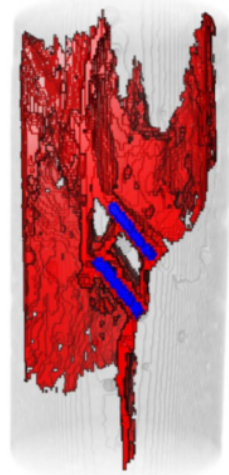

(g) Double-60 $60^{\circ}$

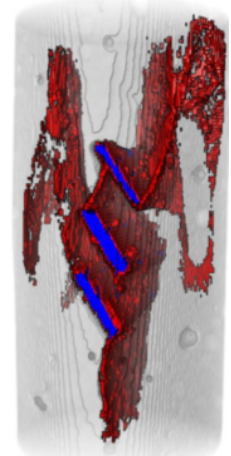

(k) Three-60 $60^{\circ}$

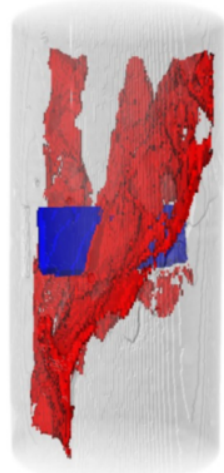

(d) Single- $90^{\circ}$

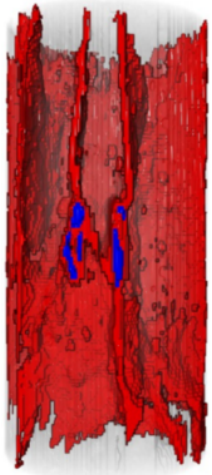

(h) Double- $90^{\circ}$

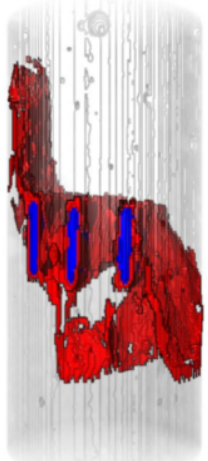

(1) Three- $90^{\circ}$

Figure 9. Crack propagation diagram of pre-fissured samples with dissimilar crack numbers (The gray shadow part is a specimen body, the blue part is a pre-fissure, the red part is a propagating crack). 
Through the above analysis, it can be known that under the conditions of horizontal and inclined fissure, the increase of fissure number only had a certain effect on the crack propagation in the specimen, but cannot change the failure mode. However, with vertical fissure conditions, fissure number increment will have a significant effect on crack propagation and failure modes.

\section{Conclusion}

(1) In this paper, through uniaxial compression test and 3D-crack reconstruction technology, the mechanical possessions and failure modes of low-strength rock samples having dissimilar fissure numbers were systematically studied. The results show that the crack number owned different degrees of degradation effects on the elastic modulus, stress-strain curve, peak strength strain, and can affect or even change the extended shape and type of cracks in the specimen.

(2) Crack number can significantly impact the stress-strain curve, especially the post-peak failure stage. The fissure number can cause the curve to slowly horizontal extending decline, with a similarity to ductile-flow distortion and failure. The findings did not occur in high-strength rock masses.

(3) Due to the structural effects, peak strength and elastic modulus lowered due to increasing crack number only under the conditions of horizontal and inclined fissures $\left(\alpha<90^{\circ}\right)$, which was negatively correlated. The axial peak strain owned an inverted Vshaped trend that increased first and then reduced because of enlarging crack number.

(4) With the inclination of the crack increased, failure modes of specimen altered from complete tensile to tensile-shear composite failure, and finally became typical shear failure. Only at vertical fissures, the increase of fissure number can completely affect the crack propagation law and change the failure mode.

\section{Acknowledgements}

This work was supported by the Chongqing Natural Science Foundation Project (Postdoctoral Science Foundation) (cstc2020jcyj-bsh0137) and Scientific research project of Chongqing Bureau of Geology and Minerals Exploration (DKJ-2020DZJ-A$015)$.

\section{References}

[1] Janeiro R P and Einstein H H 2010 Einstein, Experimental study of the cracking behavior of specimens containing inclusions (under uniaxial compression) International Journal of Fracture 164 (1) 83-102.

[2] Huang D, et al. 2016 Investigation on mechanical behaviors of sandstone with two preexisting flaws under triaxial compression Rock Mechanics and Rock Engineering 49 (2) 375-399.

[3] Park C H and Bobet A 2009 Crack coalescence in specimens with open and closed flaws: A comparison International Journal of Rock Mechanics and Mining Sciences 46 (5) 819-829.

[4] Bombolakis E G 1968 Photoelastic study of initial stages of brittle fracture in compression Tectonophysics 6 (6) 461.

[5] Yang S Q, et al. 2009 Experimental study on mechanical behavior of brittle marble samples containing different flaws under uniaxial compression Engineering Fracture Mechanics 76 (12) 1833-1845. 
[6] Yang S Q and Jing H W 2011 Strength failure and crack coalescence behavior of brittle sandstone samples containing a single fissure under uniaxial compression International Journal of Fracture $\mathbf{1 6 8}$ (2) $227-250$.

[7] Shen B 1995 The mechanism of fracture coalescence in compression-experimental-study and numerical-simulation Engineering Fracture Mechanics 51 (1) 73-85.

[8] Wong L N Y and Einstein H H 2009 Crack coalescence in molded gypsum and carrara marble: part 2microscopic observations and interpretation Rock Mechanics and Rock Engineering 42 (3) 513-545.

[9] Xiao T, Li X and Jia S 2015 Failure characteristics of rock with two pre-existing transfixion cracks under triaxial compression Yanshilixue Yu Gongcheng Xuebao/Chinese Journal of Rock Mechanics and Engineering 34 (12) 2455-2462.

[10] Manouchehrian A, et al. 2014 A bonded particle model for analysis of the flaw orientation effect on crack propagation mechanism in brittle materials under compression Archives of Civil and Mechanical Engineering 14 (1) 40-52.

[11] Renshaw C E and Schulson E M 2001 Universal behaviour in compressive failure of brittle materials Nature 412 (6850) 897-900.

[12] Lee H and Jeon S 2011 An experimental and numerical study of fracture coalescence in pre-fissured specimens under uniaxial compression International Journal of Solids and Structures 48 (6) 979-999.

[13] Li H Q and Wong L N Y 2014 Numerical study on coalescence of pre-existing flaw pairs in rock-like material Rock Mechanics and Rock Engineering 47 (6) 2087-2105.

[14] Chen X, Liao Z and Peng X 2012 Deformability characteristics of jointed rock masses under uniaxial compression International Journal of Mining Science and Technology 22 (2).

[15] Wong R H C, et al. 2002 Splitting failure in brittle rocks containing pre-existing flaws under uniaxial compression Engineering Fracture Mechanics 69 (17) 1853-1871.

[16] Zhuang X Y, Chun J W and Zhu H H 2014 A comparative study on unfilled and filled crack propagation for rock-like brittle material Theoretical and Applied Fracture Mechanics 72 110-120.

[17] Isaka B L A, et al. 2018 An influence of thermally-induced micro-cracking under cooling treatments: Mechanical characteristics of australian granite Energies 11 (6).

[18] Li Y P, Chen L Z and Wang Y H 2005 Experimental research on pre-fissured marble under compression International Journal of Solids and Structures 42 (9-10) 2505-2516.

[19] Yang S Q, et al. 2008 Experimental investigation on strength and failure behavior of pre-fissured marble under conventional triaxial compression. International Journal of Solids and Structures 45 (17) 4796-4819.

[20] Wong L N Y and Einstein H H 2009 Crack coalescence in molded gypsum and carrara marble: Part 1. macroscopic observations and interpretation Rock Mechanics and Rock Engineering 42 (3) 475-511.

[21] Rinehart A J, Bishop J E and Dewers T 2015 Fracture propagation in Indiana Limestone interpreted via linear softening cohesive fracture model Journal of Geophysical Research-Solid Earth 120 (4) 22922308.

[22] Wang Y L, et al. 2018 Experimental study on mechanical properties and failure modes of low-strength rock samples containing different fissures under uniaxial compression Engineering Fracture Mechanics $1971-20$. 